\title{
Towards a Smart Low Voltage Distribution System: An Indian Experience
}

This paper was downloaded from TechRxiv (https://www.techrxiv.org).

\section{LICENSE}

CC BY-NC-SA 4.0

SUBMISSION DATE / POSTED DATE

$11-11-2021 / 13-11-2021$

\section{CITATION}

Panigrahi, Ramanuja; Mishra, Santanu; Srivastava, Suresh C.; Enjeti, Prasad (2021): Towards a Smart Low Voltage Distribution System: An Indian Experience. TechRxiv. Preprint.

https://doi.org/10.36227/techrxiv.16989118.v1

$\mathrm{DOI}$

10.36227/techrxiv.16989118.v1 


\title{
Towards a Smart Low Voltage Distribution System: An Indian Experience
}

\author{
Ramanuja Panigrahi, Santanu K. Mishra, S. C. Srivastava \\ Department of Electrical Engineering \\ Indian Institute of Technology Kanpur, \\ Kanpur, India \\ Email: ramanuja@iitk.ac.in, santanum@iitk.ac.in, scs@iitk.ac.in
}

\author{
Prasad Enjeti \\ Department of Electrical \& Computer Engineering \\ Texas A\&M University, \\ College Station, USA \\ Email: enjeti@tamu.edu
}

\begin{abstract}
Realizing a smart Low Voltage Distribution System (LVDS) is essential to realize a smart grid. Restructuring the existing distribution system into microgrids is one important requirement to achieve a smart LVDS. The realization of microgrids in LVDS can take different shapes in different countries. This article discusses the challenges and practical solutions to realize a smart LVDS for radial distribution grids, which are common in India. The network following a distribution transformer can be distinguished as a microgrid for radial low voltage distribution grids. However, this leads to many operational issues. Therefore, this article envisions replacing the Low Voltage distribution transformers with Solid-State Transformers (SSTs). This will enable the LVDS to control the power exchange between the phases within a microgrid as well as power exchange between different microgrids. The architectural design of a smart home in smart LVDS is outlined to complete the discussion. Various unique features required for smart inverters in a smart home and existing grid codes to make them compatible with smart LVDS are also reviewed.
\end{abstract}

\section{INTRODUCTION}

The Low Voltage Distribution System (LVDS) is unbalanced in nature and highly disorganized from a load point of view. Implementation of a smart LVDS will require technological innovation in the field of power electronics and its control, apart from the overall restructuring of the low voltage distribution grid. Some important research in this field includes automation, grid-code compliance, and cybersecurity features in single-phase inverters.

Electric power is traditionally generated in generating stations far away from load centers. The transmission network takes care of transferring this power from generating stations, and the distribution network is responsible for distributing this power to end-users. The distribution system is further divided into primary and low voltage (secondary) distribution systems. The primary distribution system is easy to analyze as it electrically resembles the transmission system due to its load-balanced property. However, the LVDS is highly unbalanced and predominantly resistive in nature, with a high R/X ratio. The LVDS is differently structured depending on geographical location. For example, in North America, the LVDS is mesh-structured, as shown in Fig. 1(a) [1]. It offers redundancy to loads and is referred to as 'Secondary Networks.' The architecture of the LVDS in India is typically radial, as shown in Fig. 1(b) [2]. The LV side of the distribution transformer supplies household loads from a line and the neutral. It is also worth noting that the household loads in India, especially in semi-urban and rural areas, are lower than in Western countries.

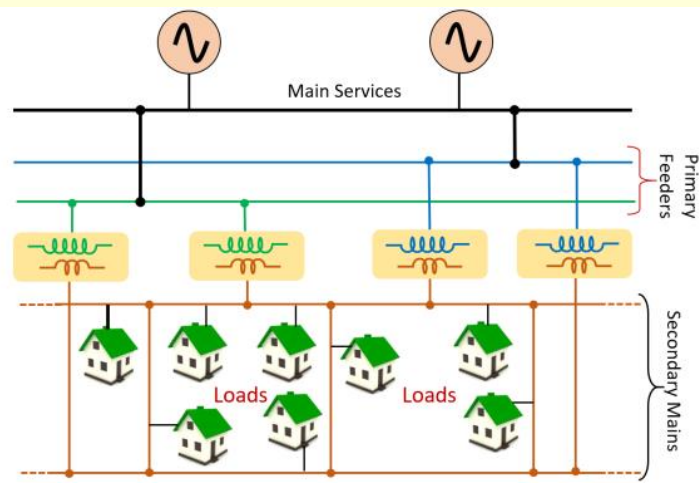

(a)

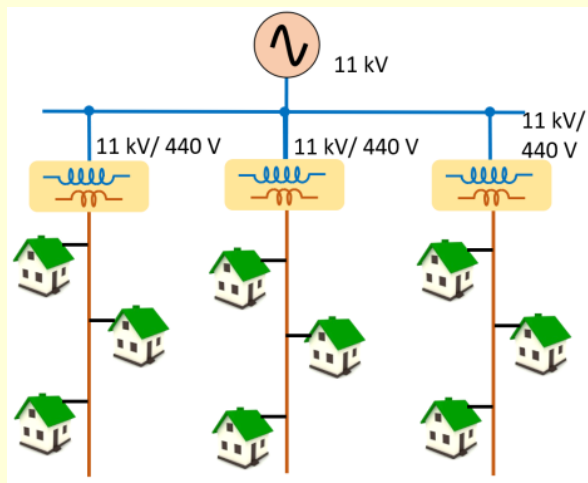

(b)

Fig. 1. A typical (a) North American distribution system and (b) Indian low voltage distribution system (LVDS). 
For the realization of an operational smart grid, it is imperative to make the existing LVDS smart. This essentially implies penetration of numerous smaller renewable installations as well as power electronics interfaces. Successful integration of a smart LVDS to the overall power grid will demand voltage control, frequency stability, reverse power flow, and protection system coordination. Different protection aspects associated with the deployment of DERs and microgrids on secondary networks are discussed in the literature. The primary protection challenges arise due to the bidirectional power flow caused by the DERs and limited fault current due to inverter-based generators.

A smart LVDS in India will be relatively unplanned and unregulated as a considerable proportion of solar Photovoltaic (PV) installation will be consumer driven. Thus, the power injection to the grid at different nodes will be unsymmetrical. The second issue that the current secondary distribution network faces is that the distribution transformers $(11 \mathrm{kV} / 440 \mathrm{~V})$ are not enabled to either control the voltage actively or to carry reverse power back to the primary distribution network. In this article, a perspective is presented to realize a smart LVDS in India.

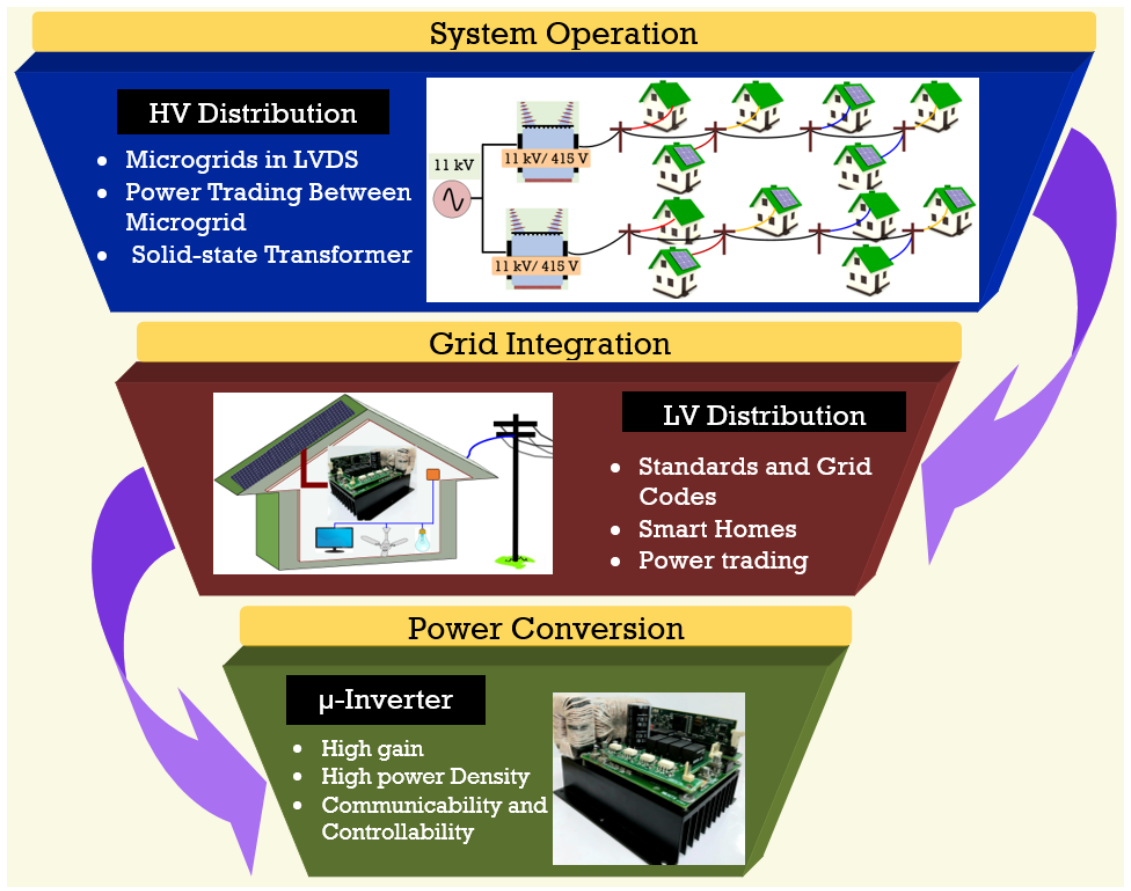

Fig. 2. A top-down approach to realize a smart LVDS.

Organization of the paper: This article follows a top-down approach, as shown in Fig. 2. Section II starts with the discussion of a microgrid and how to demarcate them in a radial LVDS. Section III discusses Solid-State Transformers (SSTs) as a replacement for the LV distribution transformers and how it will aid in smart LVDS realization. Section IV outlines the architecture of a smart home in a smart LVDS. Section V discusses the properties and operational requirements of a smart inverter in a smart home. Section VI summarizes the existing grid codes and standards relevant to PV systems and microgrids. Section VII provides some conclusions.

\section{MICROGRIDS IN SMART LVDS}

According to the US Department of Energy (DoE), a group of sources and loads can be considered a 'MICROGRID' if they satisfy the following four conditions [3].

- A clearly defined electrical boundary.

- It includes a controller to control the Distributed Energy Resources (DERs) and loads to behave as a single controllable entity.

- The installed generation capacity is greater than the peak critical load.

- An active switch to connect and disconnect it from the distribution network to shift between the grid-connected and islanded mode.

A typical microgrid is shown in Fig. 3. Now the question is, how to make the existing secondary distribution grid smart by incorporating microgrids into it? Due to the diverse nature of the LVDS, the same development template 
cannot be applied everywhere. The distribution system can be segmented into a set of independent-interconnected microgrids that may have different types of energy resources, storage capacities, load requirements, and network configurations. The potential of the DERs can be better utilized by taking a system approach and amalgamating them to form microgrids [4]. This approach also enables extensive research in the field of microgrids to be used directly in making the LVDS smart. The microgrid controller controls the operation of the microgrid, and the balance between generation and demand is drawn from or supplied to the grid.

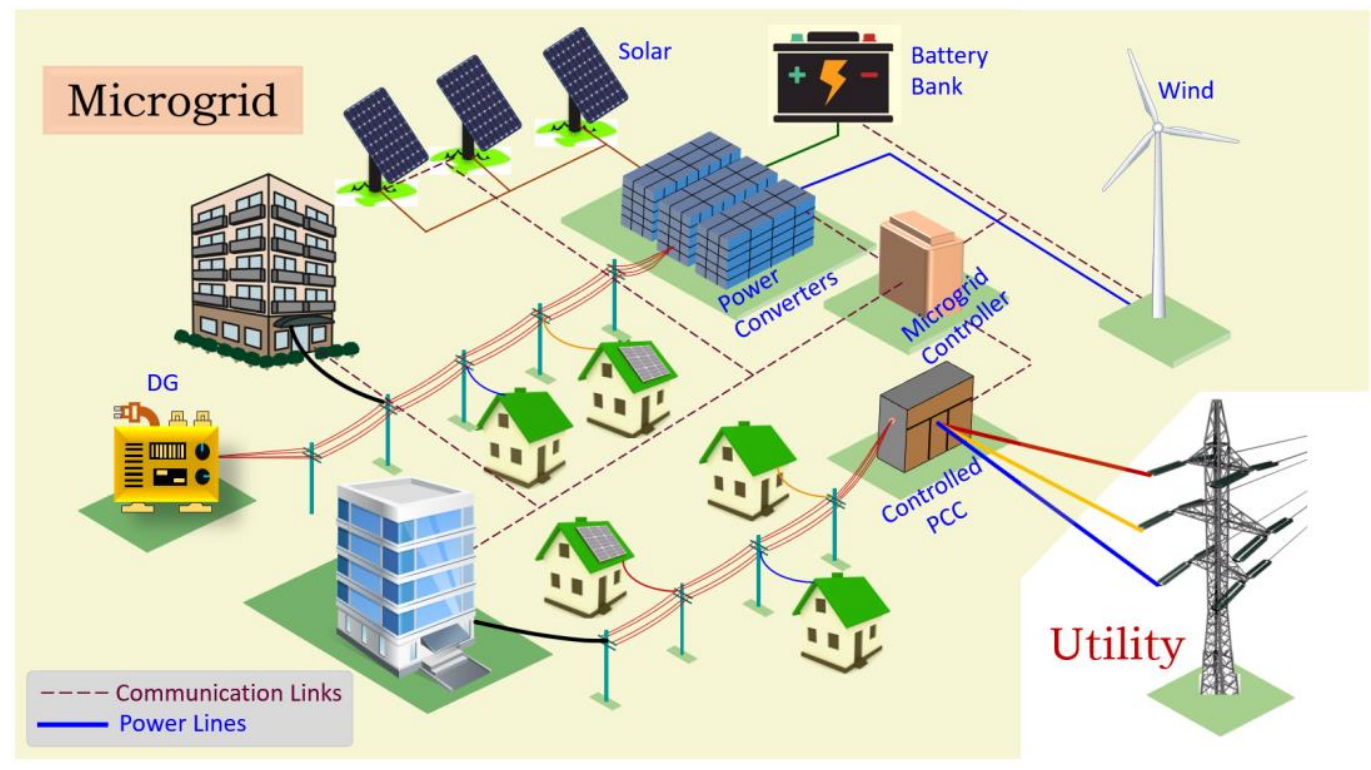

Fig. 3. The schematic of a microgrid.

An approach is to consider the network after the secondary of each distribution transformer as a separate microgrid, as shown in Fig. 4 (a). The functionality of this approach is limited by the following factors.

1) Control Switch: The distribution transformer cannot be operated as a controlled switch to toggle between grid-connected and islanded mode (Fig. 4 (a)).

2) Reverse Power Flow: Traditional transformers are neither designed to carry reverse power nor can be operated as a controlled switch. Due to this limitation, power cannot be transferred from one microgrid to another. A tie line converters or interlinking converters [5-6] can be used as a bypass link to enable power transfer between two microgrids, as shown in Fig. 4 (a). However, it is not an optimal solution for connecting many microgrids as the required number of tie-line converters will be exceedingly high.

3) Interphase Power Transfer: Renewable power-sharing is possible between the houses

\section{Kanpur Rural Microgrids: Case Study}

Indian villages consist of several hamlets distributed over a small geographical area. Two village hamlets in Harnoo village near IIT Kanpur, India were un-electrified at the start of the UI-ASSIST project. Two microgrids are developed to electrify these hamlets as shown in the figure below. A tie-line converter is used for energy sharing between the microgrids and improve reliability. This asynchronous tie line converter is made up of a bidirectional AC-DC-AC converter.

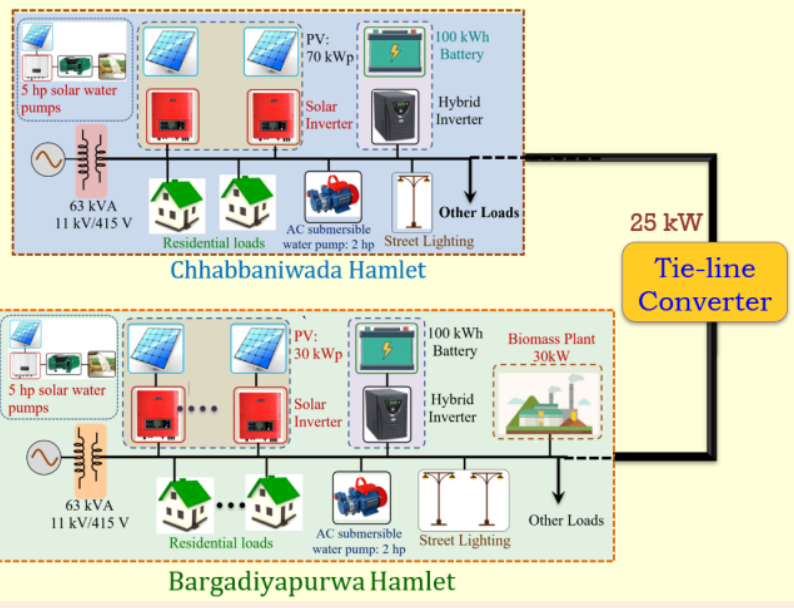


connected to the same phase (Fig. 4 (b)) but not between different phases (Fig. 4 (c)). This is due to the presence of a grounded neutral conductor.

4) Voltage Control: Due to the intermittent nature of the PV, the voltage of the distribution grid can vary significantly in high PV integration scenarios. A traditional transformer may use an on-load tap changer (OLTC) to control voltage. However, they are slow and affect the life of the transformer.

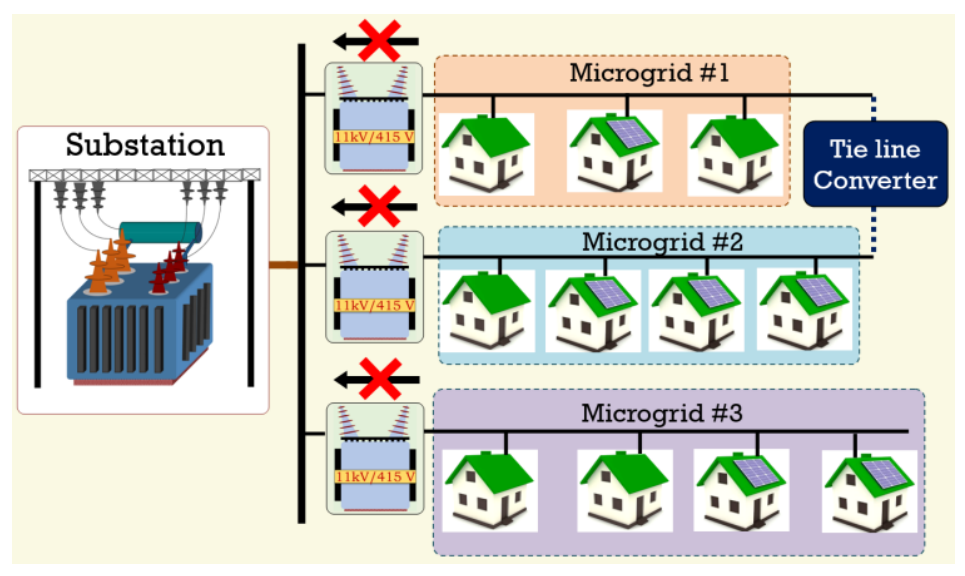

(a)

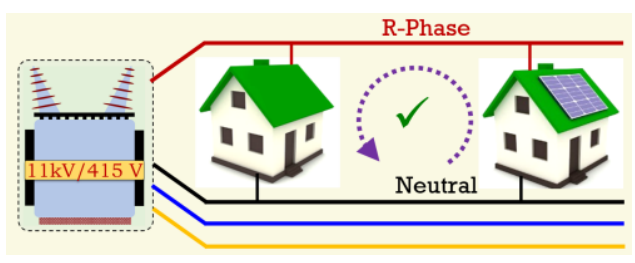

(b)

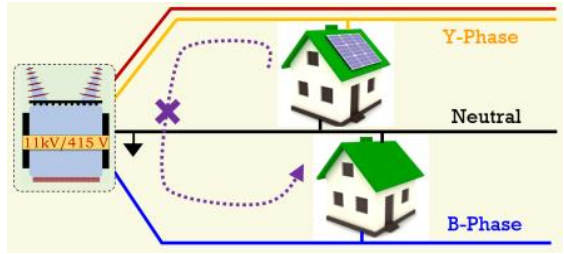

(c)

Fig. 4. Visualization of current LVDS as a combination of independent-interconnected microgrids. (b) Possibility of intra-phase power transfer and (c) Limitations on inter-phase power transfer due to the grounded neutral.

\section{SST AS A BUILDING BLOCK}

A Solid-State Transformer (SST) is envisioned as a possible candidate to eliminate the limitations imposed by the traditional transformer. SST is an AC-to-AC converter with high-frequency galvanic isolation that leads to smaller size and weight [7]. The basic structure of an SST module is shown in Fig. 5. SST can be utilized as a smart grid building block due to its modularity and controllability property [8-10].

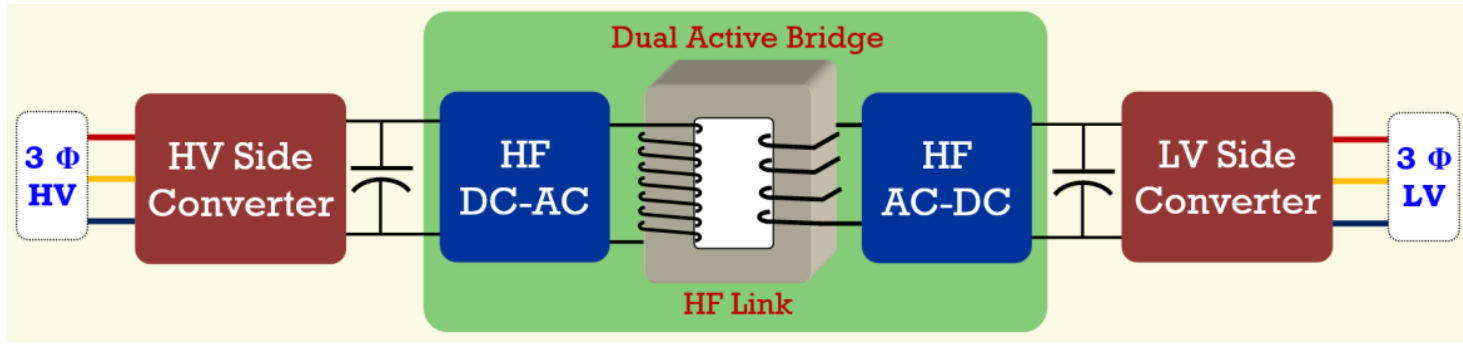

Fig. 5. Basic block diagram of a Solid-State Transformer (SST) [7-10].

The special properties of SST can be exploited to replace the existing distribution transformers, as shown in Fig. 6. This will have several advantages as given below:

1) Controlled power exchange between microgrids through the SST as reverse power flow is possible.

2) High degree of controllability of voltages, currents, power flows.

3) Power transfer between the phases within a microgrid is possible as the SST has a DC interface.

4) SST has a much faster response compared to a transformer and can be controlled to limit fault current and fault isolation. This leads to a robust smart grid. 
5) The ability of SSTs to control power flow can be used to implement energy budgeting between microgrids during disasters and extreme events.

The SST can also provide ancillary grid services such as reactive power support, harmonic mitigation, sag mitigation and short-circuit protection, and dc connectivity. However, the development of SST technology is limited due to the unavailability of switching devices in the voltage range of $13 \mathrm{kV}$. Issues such as implementation, protection, reliability, and isolation are still to be addressed.

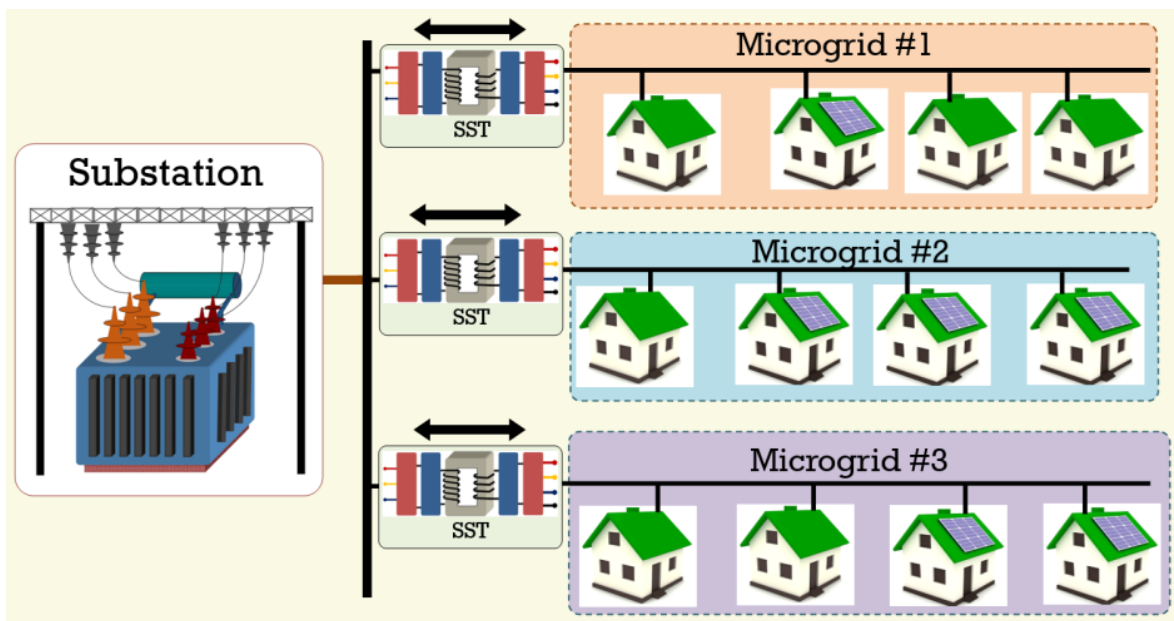

Fig. 6. SST as building blocks to make the existing LVDS smart.

\section{SMART HOMES IN SMART LVDS}

To enable the smart home [11] compatible with DMS, some non-essential loads can be interfaced to the grid using Solid State Relays (SSRs). This will allow independent control of these loads by a central microgrid control. However, critical and essential loads can still be interfaced to the LVDS/ microgrid using Miniature Circuit Breakers (MCBs) or fuses. Fig. 7 shows a smart home architecture to enable these features. Renewable power can support critical loads. Apart from supplying home loads, the power electronics in the smart home will be responsible for power exchange with the LVDS, energy budgeting, and reactive power support [11].

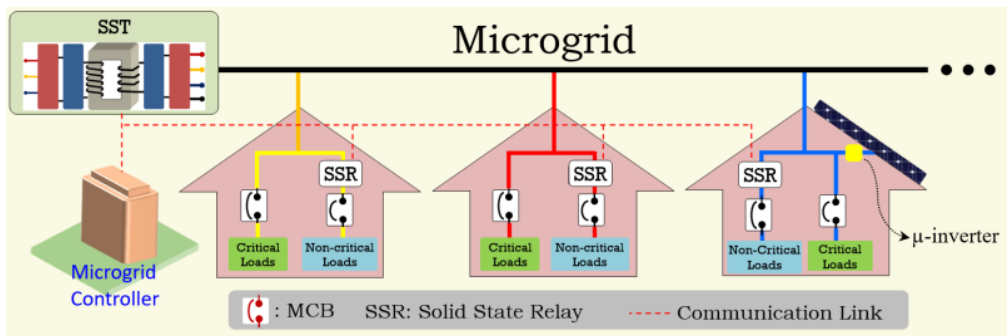

Fig. 7. Architecture of smart homes in smart LVDS.

\section{INVERTERS IN SMART LVDS}

The Smart LVDS has solar PV inverters of various sizes. At the individual house level, smaller rating single-phase inverters with or without storage support are used. They are primarily employed as a backup power supply in homes. They may work in grid-connected mode (with or without storage) or stand-alone mode (with storage). At a community level, higher power rating three-phase solar inverters are used in grid-connected mode to inject power into the distribution grid. This paper is primarily concerned with single-phase inverters. Some of the important requirements of these inverters are outlined below.

\section{A. High Conversion Ratio}

Single-phase inverters in the smart LVDS are more likely to work from a smaller number of panels due to the space and economic constraints of end-users. It is advantageous to connect the available panels in parallel rather than in series 
to harvest maximum energy during shading. Thus, the panel DC voltage available for the inverter is low, and the inverter is responsible for converting this low input DC voltage to $230 \mathrm{~V}$ or $110 \mathrm{~V} \mathrm{AC}$.

To understand why power harvest is maximum with parallel panels, take the equivalent circuit of a PV panel shown in Fig. 8 (a). It consists of a current source and an anti-parallel diode across its terminals. The cut-in voltage of the diode coincides with the maximum power point of the solar power curve. The current source output is dependent on the panel size as well as solar insolation. When panels are connected in series, the current in each panel needs to be equal. If the outputs of the panels are not identical, the minimum current among the panels will dictate the output current. This behavior is observed during partial shading, as shown in Fig. 8 (a). Thus, as shown in Fig. 8 (b), panels should be paralleled to maximize the energy harvest.

The inverters with a high conversion ratio can either be an isolated type with transformer isolation or a transformerless type. An isolated inverter uses the transformer turns ratio to achieve high gain. A transformer-less/non-isolated inverter uses a front-end boost stage to step up the solar DC output voltage to a high voltage DC-link which acts as the input to the second-stage inverter [12-13].

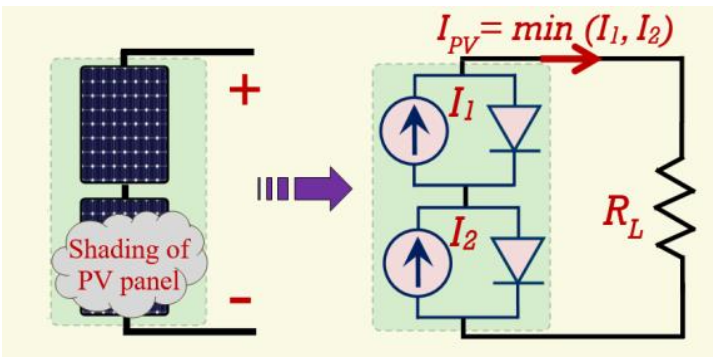

(a)

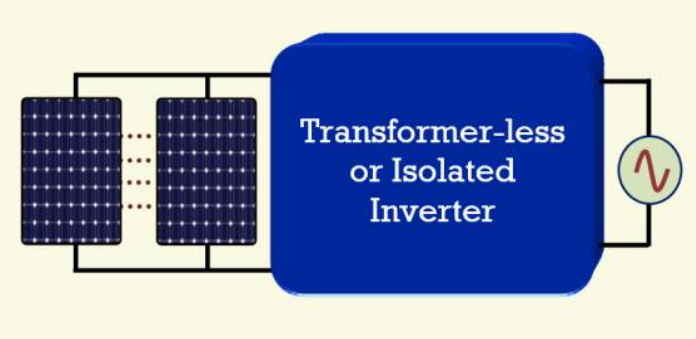

(b)

Fig. 8. (a) The equivalent circuit model of PV panels and the impact of partial shading, and (b) parallel connection of PV panels connected to a high gain power interface.

\section{B. Power Density of Inverter}

Single-phase inverters in the secondary distribution grid are designed for home applications. Therefore, they are expected to be compact, lightweight, and power-dense. Mostly high-frequency power conversion is used to implement these inverters, which leads to a smaller magnetic size. A review of topologies used in this type of application is summarized in [12]. Typically, the non-isolated inverters have higher power density and lower weight due to the absence of transformers. The primary challenges of a non-isolated inverter are to reduce the leakage current and dc injection to ensure robust inverter protection. Non-isolated inverter topologies and control philosophies are gradually being developed to address these issues [13].

\section{Load interface property}

In grid-connected mode, the inverter terminal voltage is dictated by the grid, and the inverter transfers power by injecting a current with the same frequency. Home loads are also connected to this terminal, as shown in Fig. 9 (a). Typically, the current sourced by the inverter is in phase with the grid voltage to maximize active power transfer. In stand-alone mode, the grid is disconnected from the inverter output terminals, and the inverter works as a voltage source that powers the home load. To ensure power balance under maximum power harvest by the panels, the solar power is usually routed through a battery, as shown in Fig. 9 (b). This has the added advantage of providing battery power backup. Self-organizing power electronic converters with intelligent control can also be used to connect home loads to LVDS. They can control the input power factor to be unity, enable reactive power injection, and enable energy budgeting [11]. 


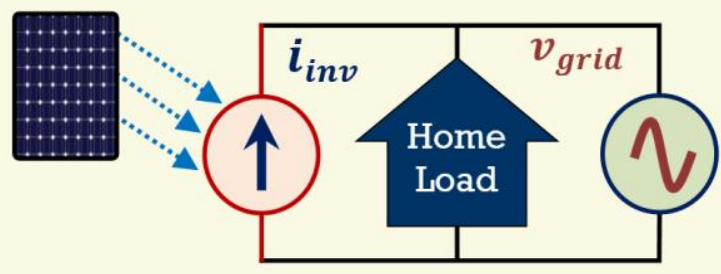

(a)

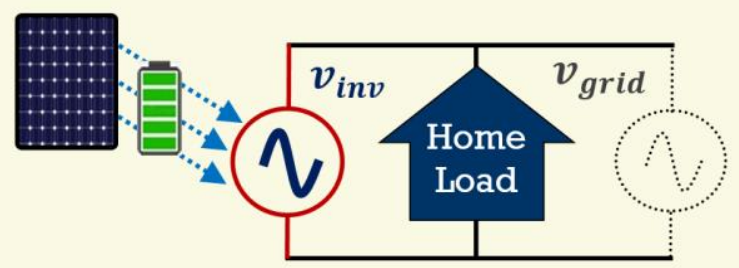

(b)

Fig. 9. Operation and equivalent representation of PV plant in (a)grid-connected mode, and (b) stand-alone mode.

\section{Communicability and Controllability}

Micro-inverters in a smart distribution grid are required to control the injected active and reactive power considering the grid conditions, PV output, and inverter VA rating. When numerous micro-inverters are present, it can lead to overvoltage and subsequent failure of the system. Therefore, it is essential to coordinate micro-inverter operations using a centralized system known as Distribution Management System (DMS) or the central microgrid controller. To work as an integral part of the smart grid, all the inverters which interact with the grid should be able to communicate with the centralized system and act based on any system coordinating instructions. Therefore, an inverter in the distribution grid should be equipped with hardware that can communicate with the DMS or the central microgrid controller and other inverters and control its output accordingly. The presence of multiple independent controllers also increases the vulnerability of the system to cyberattacks that manipulate the voltage and/or current measurements of each inverter [14]. Therefore, the inverters must be equipped to detect and mitigate cybersecurity threats. The capability to control and communicate can also enable contingency management of the inverter during fault scenarios.

\section{RULES OF PV INTEGRATION: STANDARDS AND GRID CODES}

Standards are being developed and modified to facilitate the large-scale inclusion of PVs in the existing power system while ensuring proper operation, reliability, and safety. A list of a few popular standards relevant to PV systems connected to the secondary distribution network is given in Table I. These standards dictate operational requirements (synchronization), power quality constraints (harmonics, flicker), response to abnormal grid conditions (voltage and frequency fluctuations), safety measures (islanding, leakage current, reverse power protections), and tests relevant to design, production, installation, and commissioning. The grid codes of various countries are also being upgraded to accommodate PVs and other inverter-based distributed generators in the distribution network. The recent modifications in the grid codes of China, Australia, India are focused on enabling the grid support functionalities in the inverter based DGs. Few popular standards related to the operation and control of microgrids are listed in Table II. These standards

TABLE I

POPULAR STANDARDS RELATED TO GRID-CONNECTED AND STAND-ALONE-MODE OF OPERATION OF PV SYSTEMS.

\begin{tabular}{|c|c|c|c|}
\hline \multicolumn{2}{|r|}{ Grid connected Mode } & \multicolumn{2}{|r|}{ Stand-alone Mode } \\
\hline $\begin{array}{l}\text { IEEE } 1547- \\
2018\end{array}$ & $\begin{array}{l}\text { Requirements relevant to the operation, performance, testing, safety, and } \\
\text { maintenance }\end{array}$ & \multirow{2}{*}{$\begin{array}{l}\text { IEC } \\
62124\end{array}$} & \multirow{2}{*}{$\begin{array}{l}\text { System design and performance } \\
\text { of stand-alone photovoltaic } \\
\text { systems }\end{array}$} \\
\hline \multirow{2}{*}{ IEC 61727} & \multirow{2}{*}{$\begin{array}{l}\text { Requirements for interconnection of PV systems utilizing solid-state non- } \\
\text { islanding inverters to the utility distribution system }\end{array}$} & & \\
\hline & & \multirow{3}{*}{$\begin{array}{l}\text { IEC } \\
62509\end{array}$} & \multirow{3}{*}{$\begin{array}{l}\text { Minimum requirements for } \\
\text { functioning and performance of } \\
\text { battery charge controllers used } \\
\text { with lead acid batteries in PV } \\
\text { systems }\end{array}$} \\
\hline IEC 62446-1 & $\begin{array}{l}\text { Grid connected systems - documentation, commissioning tests and } \\
\text { inspection }\end{array}$ & & \\
\hline $\begin{array}{l}\text { IEC } \\
62116: 2014\end{array}$ & $\begin{array}{l}\text { Utility-interconnected photovoltaic inverters - Test procedure of islanding } \\
\text { prevention measures }\end{array}$ & & \\
\hline $\begin{array}{l}\text { IEC } \\
62093: 2005\end{array}$ & $\begin{array}{l}\text { Requirements for the design qualification of balance-of-system (BOS) } \\
\text { components used in terrestrial photovoltaic systems }\end{array}$ & \multirow[t]{2}{*}{$\begin{array}{l}\text { IEEE } \\
1526\end{array}$} & \multirow{2}{*}{$\begin{array}{l}\text { Practice for testing the } \\
\text { performance of stand-alone } \\
\text { photovoltaic systems with a } \\
\text { defined load }\end{array}$} \\
\hline \multirow{2}{*}{ VDE-AR-4105 } & \multirow{2}{*}{$\begin{array}{l}\text { Requirements for the connection of generation and storage units to the low } \\
\text { voltage network of a network operator }\end{array}$} & & \\
\hline & & \multirow[b]{2}{*}{$\begin{array}{l}\text { IEEE } \\
1361\end{array}$} & \multirow{2}{*}{$\begin{array}{l}\text { For selecting, charging, testing, } \\
\text { and evaluating lead-acid batteries } \\
\text { used in stand-alone photovoltaic } \\
\text { systems }\end{array}$} \\
\hline AS 4777 & $\begin{array}{l}\text { Device specifications, functionality, testing and compliance requirements } \\
\text { for electrical safety and performance for inverters designed connect energy } \\
\text { sources and/or energy storage systems and the grid }\end{array}$ & & \\
\hline
\end{tabular}


TABLE II

POPULAR STANDARDS RELATED TO OPERATION AND CONTROL OF MICROGRIDS.

\begin{tabular}{|c|c|c|}
\hline Standard & Title & Description \\
\hline $\begin{array}{l}\text { IEEE 2030.5- } \\
2018\end{array}$ & $\begin{array}{l}\text { IEEE Standard for Smart } \\
\text { Energy Profile Application } \\
\text { Protocol }\end{array}$ & $\begin{array}{l}\text { Providing functions to enable utility management of end-user energy environments, including } \\
\text { demand response, load control, time-of-day pricing, management of distributed generation, } \\
\text { electric vehicles, etc. }\end{array}$ \\
\hline $\begin{array}{l}\text { IEEE 2030.7- } \\
2017\end{array}$ & $\begin{array}{l}\text { Standard for the Specification } \\
\text { of Microgrid Controllers }\end{array}$ & $\begin{array}{l}\text { Provides all the functional specifications for microgrid energy management system (MEMS) } \\
\text { regardless of topology, configuration, or jurisdiction. }\end{array}$ \\
\hline $\begin{array}{l}\text { IEEE } 2030.8- \\
2018,\end{array}$ & $\begin{array}{l}\text { Standard for the Testing of } \\
\text { Microgrid Controllers }\end{array}$ & $\begin{array}{l}\text { To develop a set of testing procedures allowing the verification, quantification, and a } \\
\text { comparison of the performance with expected minimum requirements of the different functions } \\
\text { of the microgrid controllers. }\end{array}$ \\
\hline $\begin{array}{l}\text { IEEE P2030.11, } \\
\text { (Under } \\
\text { development) }\end{array}$ & $\begin{array}{l}\text { Distributed Energy Resources } \\
\text { Management Systems } \\
\text { Functional Specification }\end{array}$ & $\begin{array}{l}\text { functional specifications for DER management systems will be important factors in designing } \\
\text { and deploying protection for DERs and microgrids. }\end{array}$ \\
\hline $\begin{array}{l}\text { IEEE P2030.12, } \\
\text { (Under } \\
\text { development) }\end{array}$ & $\begin{array}{l}\text { Draft Guide for the Design of } \\
\text { Microgrid Protection System }\end{array}$ & $\begin{array}{l}\text { Will facilitate the deployment of protection systems through different approaches to detect } \\
\text { problems and protect microgrids. The standard will address protection configuration and } \\
\text { challenges, protection system structures, modes of operation, system coordination, requirements } \\
\text { for microgrid energy management, and communication system structures. }\end{array}$ \\
\hline UL 1741 & $\begin{array}{l}\text { Standard for Inverters, } \\
\text { Converters, Controllers, and } \\
\text { Interconnection System } \\
\text { Equipment for Use with } \\
\text { Distributed Energy Resource }\end{array}$ & $\begin{array}{l}\text { These requirements cover inverters, converters, charge controllers, and interconnection system } \\
\text { equipment (ISE) intended for use in stand-alone or grid-connected power systems. Provides } \\
\text { specifications for characteristics that can impact interconnection operations and safety. } \\
\text { Supplement-A: Grid support-Utility interactive equipment } \\
\text { Supplement-B: Compatibility with IEEE } 1547.1\end{array}$ \\
\hline \multirow[t]{2}{*}{$\begin{array}{l}\text { UL } 3001 \\
\text { (Under } \\
\text { development) }\end{array}$} & \begin{tabular}{|l|} 
Safety Standard for \\
Distributed Energy and \\
Storage Systems
\end{tabular} & $\begin{array}{l}\text { Product safety standard for DERs and storage systems. Will provide insight into the } \\
\text { characteristics of DER and microgrid functionalities that facilitate protection. }\end{array}$ \\
\hline & Indian Electricity Grid Code & $\begin{array}{l}\text { IEGC lays down the rules, guidelines, and standards to be followed by various persons and } \\
\text { participants in the system to plan, develop, maintain, and operate the power system, in the most } \\
\text { secure, reliable, economic, and efficient manner. }\end{array}$ \\
\hline
\end{tabular}

discuss functional specifications, protection configurations, and testing procedures relevant to microgrid deployments in LVDS. In India, apart from the Indian Grid Code, different states are also coming up with microgrid development policies (e.g., UP mini-grid policy) to incentivize renewable-based electrification in rural areas.

\section{CONCLUSIONS}

A vision to convert the existing radial LVDS to a smart LVDS is presented in this paper. As LVDS is heterogeneous, consumer driven, and unbalanced in nature, in the developing world, incorporating distributed generation will require carefully defining energy islands or microgrids. The article proposes that the network supplied by a distribution transformer can be demarcated as a three-phase AC microgrid. The LV distribution transformer can be replaced by an SST to enable power exchange between different phases of the microgrid and with other microgrids. The realization of a smart home in smart LVDS is also discussed. The proposed connection of smart home allows an un-interfered supply of essential loads and smart interaction of non-essential loads to a central microgrid controller using DMS. Properties of a smart inverter and available grid codes for microgrid realization are also outlined to complete the discussion.

\section{REFERENCES}

[1] "Secondary Network Distribution Systems Background and Issues Related to the Interconnection of Distributed Resources", Technical Report NREL/TP-56038079. Available Online: https://www.nrel.gov/docs/fy05osti/38079.pdf

[2] A. S. Pabla, Electric Power Distribution, New Delhi: McGraw-Hill, 2012.

[3] M. Smith and D. Ton, "Key Connections: The U.S. Department of Energy’s Microgrid Initiative," in IEEE Power and Energy Magazine, vol. 11, no. 4, pp. 22-27, July-Aug. 2013.

[4] R. H. Lasseter, "Smart Distribution: Coupled Microgrids," in Proceedings of the IEEE, vol. 99, no. 6, pp. 1074-1082, June 2011, doi: 10.1109/JPROC.2011.2114630.

[5] E. Unamuno, J. Paniagua and J. A. Barrena, "Unified Virtual Inertia for ac and dc Microgrids: And the Role of Interlinking Converters," in IEEE Electrification Magazine, vol. 7, no. 4, pp. 56-68, Dec. 2019, doi: 10.1109/MELE.2019.2943978.

[6] Ander Ordono, Eneko Unamuno, Jon Andoni Barrena, Julen Paniagua, Interlinking converters and their contribution to primary regulation: a review, International Journal of Electrical Power \& Energy Systems, Volume 111, 2019, Pages 44-57, ISSN 0142-0615, https://doi.org/10.1016/j.ijepes.2019.03.057.

[7] J. E. Huber and J. W. Kolar, "Solid-State Transformers: On the Origins and Evolution of Key Concepts," in IEEE Industrial Electronics Magazine, vol. 10, no. 3, pp. 19-28, Sept. 2016, doi: 10.1109/MIE.2016.2588878.

[8] S. Bhattacharya, "Transforming the transformer," in IEEE Spectrum, vol. 54, no. 7, pp. 38-43, July 2017, doi: 10.1109/MSPEC.2017.7951721.

[9] Q. Huang, "Medium-Voltage Solid-State Transformer: Technology for a Smarter and Resilient Grid," in IEEE Industrial Electronics Magazine, vol. 10, no. 3, pp. 29-42, Sept. 2016, doi: 10.1109/MIE.2016.2589061.

[10] L. Ferreira Costa, G. De Carne, G. Buticchi and M. Liserre, "The Smart Transformer: A solid-state transformer tailored to provide ancillary services to the distribution grid," in IEEE Power Electronics Magazine, vol. 4, no. 2, pp. 56-67, June 2017, doi: 10.1109/MPEL.2017.2692381. 
[11] J. Ramos-Ruiz, B. Wang, H. Chou, P. Enjeti and L. Xie, "Power Electronics Intelligence at the Network Edge (PINE) - An Approach to Interface PV and Battery Energy Storage Systems at the Grid Edge," in IEEE Journal of Emerging and Selected Topics in Power Electronics, doi: 10.1109/JESTPE.2020.2991019

[12] K. Alluhaybi, I. Batarseh and H. Hu, "Comprehensive Review and Comparison of Single-Phase Grid-Tied Photovoltaic Microinverters," in IEEE Journal of Emerging and Selected Topics in Power Electronics, vol. 8, no. 2, pp. 1310-1329, June 2020, doi: 10.1109/JESTPE.2019.2900413.

[13] W. Li, Y. Gu, H. Luo, W. Cui, X. He and C. Xia, "Topology Review and Derivation Methodology of Single-Phase Transformer-less Photovoltaic Inverters for Leakage Current Suppression," in IEEE Transactions on Industrial Electronics, vol. 62, no. 7, pp. 4537-4551, July 2015.

[14] J. Ramos-Ruiz et al., "An Active Detection Scheme for Cyber Attacks on Grid-tied PV Systems," 2020 IEEE CyberPELS (CyberPELS), 2020, pp. 1-6, doi: 10.1109/CyberPELS49534.2020.9311539.

\section{BIBLIOGRAPHY}

\section{Distribution System and Microgrids}

[1] S. Venkata, M. Reno, W. Bower, S. Manson, J. Reilly, and G. Sey Jr., "Microgrid protection: Advancing the state of the art," Sandia National Lab., Albuquerque, NM, Tech. Rep. SAND2019-3167, Mar. 2019.

[2] M. Ropp, M. Reno, W. Bower, J. Reilly, and S. S. (Mani) Venkata, "Secondary networks and protection: Implications for DER and microgrid interconnection," Sandia National Lab., Albuquerque, NM, Tech. Rep. SAND2020-11209, Oct. 2020.

[3] A. Maitra, J. Simmons, B. Seal, and R. Sarfi, Grid Interactive Microgrid Controllers and the Management of Aggregated Distributed Energy Resources: Relationship of Microgrid Controller with DERMS and Utility DMS. Palo Alto, CA: EPRI, 2015. W. Bower et al., "The advanced microgrid-Integration and interoperability," Sandia National Lab., Albuquerque, NM, Tech Rep. SAND2014-1535, Feb. 2014.

[4] S. Manson, K.G. Ravikumar, and S.K. Raghupathula, "Microgrid systems: Design, control functions, modeling, and field experience," in Proc. Grid Future Symp., Reston, VA, Oct. 2018, pp. 1-8.

[5] W. Du, R. H. Lasseter, and A. S. Khalsa, "Survivability of autonomous microgrid during overload events," IEEE Trans. Smart Grid, vol. 10, no. 4, pp. 35153524, Apr. 2018. doi: 10.1109/TSG.2018.2829438.

[6] M. J. Reno, S. Brahma, A. Bidram and M. E. Ropp, "Influence of Inverter-Based Resources on Microgrid Protection: Part 1: Microgrids in Radial Distribution Systems," in IEEE Power and Energy Magazine, vol. 19, no. 3, pp. 36-46, May-June 2021, doi: 10.1109/MPE.2021.3057951.

[7] M. E. Ropp and M. J. Reno, "Influence of Inverter-Based Resources on Microgrid Protection: Part 2: Secondary Networks and Microgrid Protection," in IEEE Power and Energy Magazine, vol. 19, no. 3, pp. 47-57, May-June 2021, doi: 10.1109/MPE.2021.3057952.

[8] S. Brahma, "Protection of distribution system islands fed by inverter-interfaced sources," in Proc. IEEE PES PowerTech 2019, Milan, Italy. T. Patel, P. Gadde, S. Brahma, J. Hernandez-Alvidrez, and M. Reno, "Real-time microgrid test bed for protection and resiliency studies", in Proc. North American Power Symp. 2020, Tempe, AZ, April 2021.

[9] R. Sherick and R. Yinger, "Modernizing the Calfornia Grid : Preparing for a Future with High Penetrations of Distributed Energy Resources," in IEEE Power and Energy Magazine, vol. 15, no. 2, pp. 20-28, March-April 2017, doi: 10.1109/MPE.2016.2637159.

[10] "SMART DISTRIBUTION SYSTEMS Advancing the Energy Ecosystem", "Connect - January 2020". Available online: https://www.iusstf.org/assets/sitesfile/image/publications/pdf/pdf_1236007441.pdf

\section{Solid State transformers}

[11] X. She, A. Q. Huang and R. Burgos, "Review of Solid-State Transformer Technologies and Their Application in Power Distribution Systems," in IEEE Journal of Emerging and Selected Topics in Power Electronics, vol. 1, no. 3, pp. 186-198, Sept. 2013, doi: 10.1109/JESTPE.2013.2277917.

[12] M. A. Hannan et al., "State of the Art of Solid-State Transformers: Advanced Topologies, Implementation Issues, Recent Progress and Improvements," in IEEE Access, vol. 8, pp. 19113-19132, 2020, doi: 10.1109/ACCESS.2020.2967345.

[13] A. Q. Huang, "Medium-Voltage Solid-State Transformer: Technology for a Smarter and Resilient Grid," in IEEE Industrial Electronics Magazine, vol. 10, no. 3, pp. 29-42, Sept. 2016, doi: 10.1109/MIE.2016.2589061.

\section{PV Systems}

[14] R. Panigrahi, S. K. Mishra, S. C. Srivastava, A. K. Srivastava and N. N. Schulz, "Grid Integration of Small-Scale Photovoltaic Systems in Secondary Distribution Network-A Review," in IEEE Transactions on Industry Applications, vol. 56, no. 3, pp. 3178-3195, May-June 2020, doi: 10.1109/TIA.2020.2979789.

[15] S. Kouro, J. I. Leon, D. Vinnikov and L. G. Franquelo, "Grid-Connected Photovoltaic Systems: An Overview of Recent Research and Emerging PV Converter Technology," in IEEE Industrial Electronics Magazine, vol. 9, no. 1, pp. 47-61, March 2015.

[16] T. V. Thang, A. Ahmed, C. i. Kim and J. H. Park, "Flexible System Architecture of Stand-Alone PV Power Generation With Energy Storage Device," in IEEE Transactions on Energy Conversion, vol. 30, no. 4, pp. 1386-1396, Dec. 2015

\section{Standards and Grid codes}

[17] Y. K. Wu, J. H. Lin and H. J. Lin, "Standards and Guidelines for Grid-Connected Photovoltaic Generation Systems: A Review and Comparison," in IEEE Transactions on Industry Applications, vol. 53, no. 4, pp. 3205-3216, July-Aug. 2017.

[18] W. Bower and T. Key, "Status of Microgrid Protection and Related Standards and Codes: Protection Supports Integration," in IEEE Power and Energy Magazine, vol. 19, no. 3, pp. 83-92, May-June 2021, doi: 10.1109/MPE.2021.3057975.

[19] J. MacDowell et al., “A Journey Through Energy Systems Integration: Trending Grid Codes, Standards, and IEC Collaboration," in IEEE Power and Energy Magazine, vol. 17, no. 6, pp. 79-88, Nov.-Dec. 2019, doi: 10.1109/MPE.2019.2933282.

[20] A. Hoke et al., "Setting the Smart Solar Standard: Collaborations Between Hawaiian Electric and the National Renewable Energy Laboratory," in IEEE Power and Energy Magazine, vol. 16, no. 6, pp. 18-29, Nov.-Dec. 2018, doi: 10.1109/MPE.2018.2864226.

[21] IEEE Standard for Interconnecting Distributed Resources with Electric Power Systems, IEEE Std 1547-2003, Jul. 2003.

[22] Photovoltaic (PV) Systems-Characteristics of the Utility Interface, International Electrotechnical Commission (IEC), IEC 61727-2004, 2004.

[23] Indian Electricity Grid Code, Central Electricity Regulatory Commission (Indian Electricity Grid Code) (Fourth Amendment) Regulations, 2016.

[24] Uttar Pradesh Mini-Grid Policy, 2016. Available online: http://upneda.org.in/mediagallery/Mini-Grid-Policy-2016.pdf

[25] Mini-Grid Renewable Energy Generation and Supply Regulations, 2016. Available online: http://uperc.org/App_File/NotifiedUPERCMinigridregulations2016-pdf411201630132PM.pdf 